\title{
Information, loss, and the complex work of reclamation
}

On 18 April 2021, fires destroyed irreplaceable archival materials and other property at the University of Cape Town, as well as fynbos and other properties in the same area. Gas canisters at Rhodes Memorial, just above the upper campus of the University, exploded, and there was substantial damage, both on the slopes of Table Mountain and in surrounding areas.

All of us at SAJS extend our condolences to those affected by the fires. The loss of important archival material at any South African university is a loss to the entire scholarly and scientific community. There have been many reports of teams of volunteers doing what they can to salvage materials in the library, along with international efforts to collate digitised versions of documents, often collected by individual scholars. These are praiseworthy and important efforts.

At the same time, there has been serious loss to the environment, as documented by conservation ecologists. ${ }^{1}$ In the analysis of Rebelo and Esler', the issue of fynbos fires is a 'wicked problem' contributed to in part by the proliferation of alien vegetation and lack of resourcing for environmental management - all issues which many authors and supporters of our Journal are trying hard to resolve. It is not entirely clear who or what started the fires in the first place, but a number of reports have suggested that the blazes started from a small fire used by homeless people, probably for warmth and cooking. Homelessness is an issue, clearly, not just for homeless people, and an area needing attention and evidence-based input. The huge inequalities in our country are bad for everyone, not just the poor, and for the environments and heritages which we share. 'Wicked problems' like destructive fires are in their nature interdisciplinary, requiring solutions through cooperation across a range of scientific disciplines, including social scientific disciplines. It has been said many times before, but it can never be said too many times: we need to work together to address the huge challenges our country, our continent, and, indeed, the world, face.

At the same time that we in the scientific community and as South Africans and Africans contemplate the devastation of the fires and what this means for all of us, the scientific community is engaged in an exercise which will affect us all: the policy, legislative, and consultation processes related to the Protection of Personal Information Act (POPIA). It has been a pleasure and a privilege for us at SAJS to work with those who, on behalf of the entire science community, have worked exceptionally hard to produce the POPIA Code of Conduct for Research ${ }^{2}$, and to have created dedicated space for commentary and feedback in the form of the 'Discussions on POPIA' series, in which contributions receive priority publication to facilitate discussion and commentary within the tight timeframes needed. POPIA represents an important milestone in legislation affecting research in South Africa Implementation and compliance will take work and adjustment from us all, and we are grateful that debates about what POPIA is, does, and should be, have started on our pages and will continue. It is important that the science community are engaged with questions of information protection, and that, as academics and researchers we continue to debate and disagree, learning from one another. We hope that more authors will send us commentaries for review, as the realities of POPIA take hold. No document is perfect, no process without flaws, and it is our job to contest constructively and make things better.

If the fires are a story of loss and the POPIA process a story of reclamation of the rights of, amongst others, research participants, it is also important to see the links between these two issues affecting us all. There is no question that the loss of information associated with the fires is bad for research, and that reclamation in a range of ways, from the digital to the environmental, is important. But there are other, less obvious, issues at stake. It has become a cliché to say that history is written by the victors, with the exact origins of that formulation, and related formulations, being contested. But issues of representation and participation in scholarship need our attention. Behind the long POPIA process, going back years, is the question, amongst others, of the rights of those who are researched to be recognised as agents in their own lives and not just as data, the objects of the gaze of the more powerful. POPIA engages with the question of people's rights to consent (or not consent) to information about them or from them to be used. In many of our archives all over the world we have documents and stories which are told without the consent of the central characters, narratives which may and do have many good qualities but which may also contribute to continued othering of people positioned as objects of research. Archival scholars have begun a long recuperative process not just to consider the importance of protecting the archive - however complex and laden with histories of power, inclusion and exclusion that archive may be - but also to think about and research information not properly archived, if archived at all. This lack of archiving, as a number of scholars including Phalafala ${ }^{3,4}$ have shown, differentially excludes voices of the less powerful from what is commonly viewed as knowledge in our context, and indeed, globally.

Part of the work of science is that of reclamation and restoration. Maintaining our world is indeed a 'wicked problem', which many people in our science community are working on. Part of the maintenance and development of our world lies not only in protecting people's rights to some control over the information they supply to us, but also in recognising and interrogating information and knowledges which have been suppressed. Science is changing, and there is much to celebrate in this regard, but we still have some way to go in incorporating, drawing from, and engaging critically with the voices of those who have been, and continue to be, excluded. The Cape Town fires started at Rhodes Memorial, and the name Rhodes, of course, has been associated with tumult and upheaval in our scholarship systems. We need also to think about who else needs to be remembered and engaged with, in such a way that respects both their right to privacy and their right to be active participants in the research conversation.

\section{References}

1. Rebelo A, Esler KJ. Why the fire on Cape Town's iconic Table Mountain was particularly devastating. The Conversation. 2021 April 20. Available from: https://theconversation.com/why-the-fire-on-cape-towns-iconic-tablemountain-was-particularly-devastating- 159390

2. Adams R, Adeleke F, Anderson D, Bawa A, Branson N, Christoffels A, et al. POPIA Code of Conduct for Research. S Afr J Sci. 2021;117(5/6), Art \#10933. https://doi.org/10.17159/sajs.2021/10933

3. Phalafala UP. Polyglot internationalism and the matriarchive: The case of Keorapetse Kgositsile. Interventions. 2020;22(3):346-363. https://doi.org/ 10.1080/1369801X.2020.1718539

4. Phalafala UP. The matriarchive as life knowledge in Es'kia Mphahlele's African humanism. a/b Auto/Biography Stud. 2020;35(3):729-747. https://doi.org/1 $0.1080 / 08989575.2020 .1762999$ 